\title{
HUBUNGAN KOMUNIKASI TERAPEUTIK BIDAN DENGAN KECEMASAN IBU BERSALIN DI PUSKESMAS BERANGAS KABUPATEN BARITO KUALA TAHUN 2021
}

\author{
Sri Norlina \\ Akademi Kebidanan Bunga Kalimantan \\ Email: srynorina@yahoo.com
}

\begin{abstract}
Childbirth is one of the most difficult times for mothers. The birth process is like a life and death gamble for a mother. Anxiety, panic, and fear that hit can interfere with the delivery process, increase pain, muscles become tense, and mother becomes tired quickly and labor takes a long time. Therapeutic communication is communication that is consciously planned, aimed, and focused on the patient's recovery. There are many assumptions that state that therapeutic communication can help mothers go through the labor process better. The purpose of this study was to determine the relationship between midwife therapeutic communication and maternal anxiety at the Berangas Health Center, Barito Kuala Regency in 2021. Correlative descriptive research method with cross sectional approach was the research method used in this study. The population in this study were mothers who came to the Puskesmas. The research sample was 42 people, taken using purposive sampling technique. The research was conducted at the Berangas Public Health Center, Kab. Barito Kuala in January until March 2021. The results showed that most of the midwives carried out therapeutic communication in the sufficient category, namely 50\%, most of the respondents experienced moderate anxiety, which was $61.9 \%$. The results of statistical tests with Kendall Tau analysis obtained correlation coefficient $-0,439$ with $\rho$ value of 0,0006 ( $\rho$ value < 0,05). This study shows that there was a correlation of therapeutic communication on maternal anxiety. This study concludes that therapeutic communication helps overcome anxiety in maternity and is highly recommended to be given to maternity mothers during the labor process.
\end{abstract}

Keywords: Communication, Maternal Anxiety, Therapeutic.

\begin{abstract}
ABSTRAK
Persalinan merupakan salah satu masa yang cukup berat bagi ibu. Proses persalinan layaknya sebuah pertaruhan hidup dan mati seorang ibu. Rasa cemas, panik, dan takut yang melanda dapat mengganggu proses persalinan, meningkatkan rasa nyeri, otot-otot menjadi tegang dan ibu menjadi cepat lelah serta persalinan menjadi lama. Komunikasi terapeutik adalah komunikasi yang direncanakan secara sadar, bertujuan dan dipusatkan untuk kesembuhan pasien. Banyak anggapan yang menyatakan bahwa komunikasi terapeutik dapat membantu Ibu menjalani proses persalinan dengan lebih baik. Tujuan penelitian ini untuk mengetahui hubungan komunikasi terapeutik bidan dengan kecemasan ibu bersalin di Puskesmas Berangas Kabupaten Barito Kuala pada Tahun 2021. Metode penelitian deskriptif korelatif dengan pendekatan Cross sectional adalah metode penelitian yang digunakan dalam penelitian ini. Populasi dalam penelitian ini adalah ibu bersalin yang datang ke Puskesmas. Sampel penelitian 42 orang, diambil menggunakan teknik purposive sampling. Penelitian dilakukan di Puskesmas Berangas Kab. Barito Kuala pada bulan Januari - Maret 2021. Hasil penelitian menunjukkan sebagian besar bidan melaksanakan komunikasi terapeutik dengan kategori cukup yaitu $50 \%$, sebagian besar responden mengalami kecemasan dengan tingkat sedang yaitu sebesar $61,9 \%$. Hasil uji korelasi Kendall Tau diperoleh nilai koefisien korelasi sebesar -0,439 dengan nilai $\rho$ sebesar 0,0006 ( $\rho$ value $<0,05$ ), Penelitian ini menunjukkan ada hubungan komunikasi terapeutik dengan kecemasan ibu bersalin. Penelitian ini menyimpulkan bahwa komunikasi terapeutik membantu mengatasi kecemasan pada ibu bersalin, dan sangat direkomendasikan diberikan kepada ibu bersalin selama proses persalinan.
\end{abstract}

Kata kunci: Kecemasan ibu bersalin, Komunikasi, Terapeutik. 


\section{PENDAHULUAN}

Kesehatan adalah hak asasi dari setiap manusia. Manusia sebagai warga Negara memiliki hak untuk dilindungi haknya mendapatkan pelayanan kesehatan dari Negara. Bidan sebagai salah satu tenaga kesehatan sangat berperan dalam meningkatkan derajat kesehatan masyarakat, khususnya kesehatan Ibu dan Anak. Bidan mempunyai tugas untuk memberikan pelayanan kebidanan yang meliputi pelayanan antenatal, pelayanan intranatal dan pelayanan nifas secara normal. Salah satu masa yang cukup berat bagi ibu adalah persalinan, dimana proses melahirkan layaknya sebuah pertaruhan hidup dan mati seorang ibu. Rasa cemas, panik, dan takut yang melanda dapat mengganggu proses persalinan, meningkatkan rasa nyeri, otot-otot menjadi tegang dan ibu menjadi cepat lelah serta mengakibatkan lamanya proses persalinan (Susanti, 2011).

Kecemasan dan ketakutan dapat mengakibatkan rasa nyeri yang hebat dan juga dapat mengakibatkan menurunnya kontraksi uterus, sehingga persalinan akan bertambah lama. Bukan hanya partus lama, menurut Qiu, et all, ibu dengan gangguan kecemasan juga berkaitan dengan resiko preeklampsia yang meningkat. Ruth, Wendy (2014) menyatakan bahwa stres, ketakutan, dan ansietas dapat meningkatkan tekanan darah dengan menstimulasi system saraf simpatik (sindrom "white coat") merujuk pada hipertensi terkait ansietas yang terjadi akibat mendatangi ligkungan perawatan kesehatan (Trisiani, 2016).

Maryunani (2010) menjelaskan bahwa kecemasan yang dialami oleh ibu pada awal persalinan berhubungan dengan berbagai macam faktor yang terkait dengan proses persalinan. Alasan mendasar yang membuat ibu cemas menghadapi persalinan ini seperti rasa nyeri pada waktu persalinan, ibu melahirkan normal atau dengan SC, bayi lahir selamat atau tidak, ibu selamat atau tidak, dan pembiayaan setelah persalinan. Cara untuk mengurangi kecemasan pada ibu antara lain: bidan memberikan informasi serta mengedukasi ibu untuk mengetahui ketakutan yang jelas, membuat hubungan kerjasama dengan pendamping, menjadi pendengar yang baik, menunjukkan sikap simpatik, membantu dan komunikatif terhadap ibu yang akan bersalin. Salah satu upaya untuk mengurangi kecemasan tersebut adalah dengan menerapkan asuhan sayang ibu yang didalam penerapannya menggunakan teknik-teknik komunikasi terapeutik.

Komunikasi merupakan salah satu bentuk kewajiban penolong terhadap hak pasien untuk memperoleh informasi objektif dan lengkap tentang apa yang dialaminya. Komunikasi yang baik akan sangat membantu terbinanya hubungan antar manusia yang serasi diantara pasien dan penolong, keserasian hubungan sangat diperlukan dalam memperoleh rasa saling percaya (Safuddin, 2004).

Komunikasi terapeutik adalah komunikasi yang direncanakan secara sadar, bertujuan dan dipusatkan untuk kesembuhan pasien. Komunikasi terapeutik mengarah pada bentuk komunikasi interpersonal. Komunikasi terapeutik adalah kemampuan atau keterampilan bidan untuk membantu pasien beradaptasi terhadap stres, mengatasi gangguan psikologis, dan belajar bagaimana berhubungan dengan orang lain. Komunikasi terapeutik merupakan hubungan interpesonal antara bidan dengan pasien, dalam hubungan ini bidan dan pasien memperoleh pengalaman belajar bersama dalam rangka memperbaiki pengalaman emosional pasien (Lusa, 2009).

Uraian yang sudah dipaparkan di atas membuat peneliti tertarik untuk mengetahui hubungan komunikasi terapeutik bidan dengan kecemasan ibu bersalin di Puskesmas Berangas Kabupaten Barito Kuala Tahun 2021.

\section{METODE PENELITIAN}

Penelitian ini menggunakan metode penelitian deskriptif korelatif dengan pendekatan Cross sectional. Data yang gunakan adalah data primer, yang dikumpulkan dari responden dengan menggunakan kuesioner untuk menilai komunikasi terapeutik dan tingkat kecemasan Ibu bersalin. Pengumpulan data ini dilakukan dengan cara melakukan wawancara kepada Ibu bersalin menggunakan panduan pertanyaan dalam kuesioner. Setelah data terkumpul kemudian dilakukan analisis statistik dengan komputerisasi. Pemilihan sampel dalam penelitian ini dilakukan dengan menggunakan teknik purposive sampling. Sampel dalam penelitian ini yaitu ibu bersalin yang melakukan pemeriksaan ke Puskesmas Berangas Kab. Barito Kuala pada bulan Januari-Maret 2021 sebanyak 42 orang. Data yang diperoleh dianalisis menggunakan statistik non parametrik untuk mencari hubungan dan menguji hipotesis yaitu korelasi Kendal Tau dengan menggunakan teknik komputerisasi dengan program SPSS.

\section{HASIL}

Data hasil penelitian disajikan secara analisis univariabel dan bivariabel. Hasil analisis univariat didapatkan gambaran distribusi frekuensi dari masing-masing variabel.

Tabel 1. Distribusi Frekuensi Responden berdasarkan umur dan tingkat pendidikan.

\begin{tabular}{llll}
\hline No & Variabel & F & \% \\
\hline $\mathbf{1}$ & Umur & & \\
\hline & $<20$ & 1 & 2,38 \\
\hline & $20-35$ & 36 & 85,71 \\
\hline & $>35$ & 5 & 11,91 \\
\hline & Jumlah & 42 & 100 \\
\hline $\mathbf{2}$ & Tingkat Pendidikan & & \\
\hline & Dasar & 14 & 33,33 \\
& Menengah & & 73,81 \\
\hline & Menengah & 23 & 54,76 \\
\hline & Tinggi & 5 & 11,91 \\
\hline & Jumlah & 42 & 100 \\
\hline
\end{tabular}

Tabel 1 menunjukkan bahwa sebagian besar ibu bersalin berumur 20-35 tahun yaitu sebanyak 36 orang $(85,71 \%)$. Sedangkan, sebagian besar ibu bersalin dengan pendidikan tingkat menengah yaitu sebanyak 23 orang $(54,76 \%)$. 
Tabel 2. Distribusi Frekuensi Responden berdasarkan paritas

\begin{tabular}{cccc}
\hline No & Paritas & F & \% \\
\hline 1 & Primipara & 3 & 7,14 \\
2 & Multipara & 31 & 73,81 \\
3 & Grandemultipara & 8 & 19,05 \\
\hline & Jumlah & 42 & 100 \\
\hline
\end{tabular}

Tabel 2 menujukkan bahwa sebagian besar ibu bersalin dengan status paritas multipara (2-4) yaitu sebanyak 31 orang $(73,81 \%)$.

Tabel 3. Distribusi Frekuensi Pelaksanaan Komunikasi Terapeutik

\begin{tabular}{cccc}
\hline No & $\begin{array}{c}\text { Komunikasi } \\
\text { Terapeutik }\end{array}$ & f & \% \\
\hline 1 & Baik & 12 & 28,57 \\
2 & Cukup & 21 & 50 \\
3 & Kurang & 9 & 21,43 \\
\hline & Jumlah & 42 & 100 \\
\hline
\end{tabular}

Tabel 3 menggambarkan bahwa sebagian besar bidan melaksanakan komunikasi terapeutik dengan kategori cukup yaitu $50 \%$.

Tabel 4. Distribusi Frekuensi tingkat kecemasan ibu bersalin

\begin{tabular}{|c|c|c|}
\hline No Tingkat Kecemasan & $\mathbf{f}$ & $\%$ \\
\hline Ringan & 11 & 26,19 \\
\hline Sedang & 26 & 61,9 \\
\hline Berat & 5 & 11,91 \\
\hline Jumlah & 42 & 100 \\
\hline
\end{tabular}

Tabel 4 dapat menggambarkan bahwa sebagian besar responden mengalami kecemasan dengan tingkat sedang yaitu sebesar $61,9 \%$.

Tabel 5 Pengaruh komunikasi terapeutik bidan dengan kecemasan ibu bersalin

\begin{tabular}{lcccccccc}
\hline Komuni & \multicolumn{9}{c}{ Tingkat Kecemasan } & \multicolumn{2}{c}{ Total } \\
\cline { 2 - 9 } $\begin{array}{c}\text { kasi } \\
\text { Terapeut } \\
\text { ik }\end{array}$ & Ringan & \multicolumn{2}{c}{ Sedang } & \multicolumn{3}{c}{ Berat } & & \\
\cline { 2 - 9 } & f & $\mathrm{f}$ & $\%$ & $\mathrm{f}$ & $\%$ & $\mathrm{f}$ & $\%$ \\
\hline Baik & 7 & 16,67 & 4 & 9,52 & 1 & 2,38 & 12 & 28,57 \\
\hline Cukup & 3 & 7,14 & 16 & 38,10 & 2 & 4,76 & 21 & 50 \\
\hline Kurang & 1 & 2,38 & 6 & 14,28 & 2 & 4,76 & 9 & 21,42 \\
\hline Jumlah & 11 & 26,19 & 26 & 61,90 & 5 & 11,91 & 42 & 100.0 \\
\hline
\end{tabular}

Tabel 5 menunjukkan bahwa sebagian besar responden yang mendapatkan komunikasi terapeutik dalam kategori cukup dengan tingkat kecemasan sedang yaitu sebanyak 21 orang $(50 \%)$ dan dari 9 orang $(21,42 \%)$ responden yang mendapatkan komunikasi terapeutik dalam kategori kurang terdapat 2 orang $(4,76 \%)$ yang mengalami kecemasan tingkat berat saat bersalin.
Hasil uji korelasi Kendall Tau menunjukkan nilai koefisien korelasi sebesar -0,439 dengan nilai $\rho$ sebesar 0,0006 ( $\rho$ value $<0,05$ ). Hal ini menunjukkan adanya hubungan komunikasi terapeutik terhadap kecemasan ibu bersalin di Puskesmas Berangan Kabupaten Barito Kuala. Nilai koefisien korelasi negatif menunjukkan bahwa hubungan yang berbanding terbalik, dimana semakin baik komunikasi terapeutik yang dilakukan oleh Bidan maka akan semakin ringan kecemasan yang dirasakan ibu bersalin.

\section{PEMBAHASAN}

Notoatmojo (2005) menunjukkan bahwa komunikasi merupakan terminologi untuk menunjuk pada suatu proses pertukaran informasi. Komunikasi mencakup segala bentuk interaksi dengan orang lain yang berupa percakapan biasa, advokasi dan negosiasi. Komunikasi yang dilakukan Bidan dalam proses persalinan antara lain dilakukan dalam bentuk Asuhan Sayang Ibu. Asuhan sayang Ibu adalah asuhan yang saling menghargai budaya, kepercayaan dari keinginan sang ibu pada asuhan yang aman selama proses persalinan serta melibatkan ibu dan keluarga sebagai pembuat keputusan, tidak emosional dan sifatnya mendukung.

Ibu yang akan bersalin pasti mempunyai emosi berlebihan yang dapat menimbulkan suatu kecemasan. Kecemasan yang timbul dapat disebabkan karena dua faktor yaitu antara kesenangan dan rasa nyeri yang sedang dirasakan. Salah satu bentuk kecemasannya adalah berupa ansietas primer yang timbul karena tauma kelahiran (birth trauma), dimana merupakan dasar bagi timbulnya neurotic anxiety. Salah satu bentuknya adalah free-floating anxiety yaitu suatu keadaan cemas dimana individu selalu menantikan sesuatu yang buruk yang mungkin terjadi. Akibatnya ia akan selalu berada dalam keadaan cemas karena takut menghadapi akibat yang akan buruk dalam situasi yang tidak menentu (Varney, 2001).

Maryunani (2010) menjelaskan bahwa kecemasan yang dialami oleh ibu pada awal persalinan berhubungan dengan berbagai macam faktor yang terkait dengan proses persalinan. Alasan mendasar yang membuat ibu cemas menghadapi persalinan ini seperti rasa nyeri pada waktu persalinan, ibu melahirkan normal atau dengan SC, bayi lahir selamat atau tidak, ibu selamat atau tidak, dan pembiayaan setelah persalinan. Cara untuk mengurangi kecemasan pada ibu antara lain: bidan memberikan informasi serta mengedukasi ibu untuk mengetahui ketakutan yang jelas, membuat hubungan kerjasama dengan pendamping, menjadi pendengar yang baik, menunjukkan sikap simpatik, membantu dan komunikatif terhadap ibu yang akan bersalin. Salah satu upaya untuk mengurangi kecemasan tersebut adalah dengan menerapkan asuhan sayang ibu yang didalam penerapannya menggunakan teknik-teknik komunikasi terapeutik.

Komunikasi terapeutik merupakan kemampuan atau keterampilan bidan untuk membantu klien beradaptasi terhadap stres, mengatasi gangguan psikologis, dan belajar bagaimana berhubungan dengan orang lain (Lusa, 2009). Komunikasi terapeutik adalah komunikasi yang direncanakan secara sadar, bertujuan dan dipusatkan untuk 
kesembuhan klien. Komunikasi terapeutik mengarah pada bentuk komunikasi interpersonal. Komunikasi terapeutik yang baik dapat membantu klien dalam mengatasi kecemasan yang dihadapinya (Siti Fatmawati, 2010). Dalam Jurnal Promosi Kesehatan Indonesia (2014) dijelaskan bahwa melakukan kegiatan komunikasi terapeutik sangat penting bagi tenaga kesehatan yang akan memberikan pelayanan, namun masih sangat minim yang menerapkan pelaksanaan komunikasi terapeutik. Pada Fase orientasi, sebanyak $66,7 \%$ responden di RS Pemerintah tidak pernah memperkenalkan diri, tidak pernah menanyakan nama panggilan kesukaan pasien dan tidak pernah menjelaskan waktu yang dibutuhkan untuk melakukan kegiatan komunikasi terapeutik. Padahal dengan menanyakan hal ini berarti pemberi pelayanan kesehatan telah bersikap terbuka dan berusaha membina rasa saling percaya, dimana Stuart (1998) menyatakan bahwa hubungan saling percaya merupakan kunci dari keberhasilan suatu hubungan terapeutik.

Hasil penelitian menunjukkan bahwa adanya hubungan antara komunikasi terapeutik yang dilakukan bidan dengan kecemasan ibu bersalin yang berbanding terbalik, dimana semakin baik komunikasi terapeutik yang dilakukan oleh Bidan maka akan semakin ringan kecemasan yang dirasakan ibu bersalin. Jika ibu diperhatikan dan mengetahui dengan baik mengenai proses persalinan dan asuhan yang akan mereka terima, mereka akan mendapatkan rasa aman dan hasil yang baik, seperti bidan memberikan informasi mengenai proses alami yang dialami oleh tubuh ibu saat hamil dan bersalin, menanyakan keluhan yang ibu rasakan, melakukan pendekatan sehingga mampu membuat ibu percaya diri bisa melewati proses persalinan dengan baik, memberikan penentraman hati, kontak fisik misalnya menggosok punggung ibu dan memegang tangannya, serta sikap ramah yang konstan memberi rasa nyaman oleh pemberi perawatan wanita secara signifikan dapat mengurangi rasa cemas ibu, sehingga persalinan berlangsung secara fisiologis serta mencegah adanyaintervensi dalam proses persalinan seperti vacum extraction, cunam dan SC.

\section{KESIMPULAN}

Penelitian ini menunjukkan adanya hubungan antara praktik pemberian komunikasi terapeutik terhadap tingkat kecemasan ibu bersalin. Penelitian ini menunjukkan bahwa untuk meningkatkan pelayanan kesehatan pada ibu bersalin, dapat dilakukan dengan pengelolaan penerapan komunikasi teurapetik, dengan memasukkan komunikasi terapeutik dalam SOP Asuhan Persalinan oleh bidan.

Pelaksanaan komunikasi terapeutik yang mendasar adalah mendengarkan ungkapan perasaan ibu. Seperti halnya yang diungkapkan Cristina dkk (2003) yang menyatakan dalam pelaksanaan komunikasi terapeutik bidan harus mampu mendengarkan masalah yang disampaikan klien dengan penuh perhatian. Proses ini akan membuat rasa aman pada klien sehingga dapat mengeluarkan semua beban yang ada, sehingga ibu akan lebih siap dalam menghadapi persalinan.

Diharapkan kepada Bidan serta tenaga kesehatan yang berperan dalam proses persalinan dengan adanya komunikasi terapeutik khususnya berkaitan dengan fisiologi persalinan dari bidan dan tenaga kesehatan lain dapat membantu ibu bersalin untuk mengurangi beban perasaan dan pikiran serta dapat mengambil tindakan untuk mengubah situasi yang ada, mengurangi keraguan, membantu dalam hal mengambil tindakan yang efektif sehingga kecemasan yang dialami dapat berkurang.

\section{AKNOWLEDGEMENT}

Ucapan terima kasih penulis sampaikan kepada semua pihak yang sudah berkontribusi menyukseskan penelitian ini sampai akhir, terutama kepada Puskesmas Berangas, Kabupaten Barito Kuala dan Akademi Kebidanan Bunga Kalimantan.

\section{DAFTAR PUSTAKA}

Cristina Lia, dkk. (2003). Komunikasi Kebidanan.Jakarta:EGC

Depkes RI, 2000, Alat Bantu Pembinaan Bidan di Desa dalam menunjang Kemitraan pertolongan persalinan Dukun Paraji dan Bidan di Desa Jawa Barat. Depkes RI, 2001, Komunikasi Efektif, Jakarta

Depkes RI, 2002, Standar Profesi Kebidanan, Jakarta.

Depkes RI, 2010, Standar pelayanan Kebidanan, Jakarta. Kotler, Philip, 2002, Manajemen Pemasaran, Edisi milenium diterjemahkan oleh Hendra Teguh, Ronny A, Rusli, dan Benyamin Molan, Jakarta: Prenhalindo.

Lusa. (2009). Faktor Yang Mempengaruhi Komunikasi. [online]. Tersedia di : www.lusa.web.id

Maryunani Ani. (2016). Managemen Kebidanan Terlengkap. Jakarta : CV. Trans Info Media

Notoatmodjo, 2005, Promosi kesehatan, Teori dan aplikasi, Jakarta, Rineka Cipta.

Saefudin AB, 2002, Ilmu Kebidanan, Edisi Ketiga Cetakan ke 7 Yayasan Bina Pustaka Sarwono Prawirohardjo, Jakarta.

Singgih G,2006, Psikologi praktis: Anak, Remaja dan Keluarga, Jakarta, Gunung Mulia.

Siti Fatmawati. (2010). Komunikasi Keperawatan Plus Materi Komunikasi Terapeutik. Yogyakarta : Nuha Medika

Tjiptono,2000, Strategi Pemasaran, Edisi 2, cetakan ketiga, Yogyakarta: Andi

Trisiani, D. (2016). Hubungan Kecemasan Ibu Hamil terhadap Kejadian Preeklampsia.Jurnal Ilmiah Bidan, 1(3), 14-18.

Walyani Siwi Elisabet Pe. Komunikasi dan Konseling dalam Kebidanan. Yogyakarta: Pustaka Baru Press; 2015 